\title{
Measurement and Evaluation of Bills Sent by Power Utility Companies to Consumers of Electricity in Nigeria
}

\author{
ONYEORU, HC \\ Department of Electrical and Electronic Engineering, Delta State University, Abraka, Nigeria. \\ AuthorEmail:chihap80@yahoo.com
}

\begin{abstract}
The present method of Electricity Billing in Nigeria is very elaborate cumbersome, and inaccurate. In this method, consumers of Electricity are not properly billed according to the energy they consumed. No accurate method of determining consumer's energy consumption by PUC has been made public. Rather, they choose to bill consumers arbitrarily.This has not only made consumers to pay for energy not consumed or are left to huge amount of money as debt accrued to the Power Company involved. This has continued to generate rancor and acrimonies among consumers and staff of PUC who would want the former to pay for the huge debt they are owing by all means. This investigation therefore seek ways of finding lasting solution to eradicate the imbroglio among consumers and suppliers of Electricity nationwide.
\end{abstract}

\section{DOI: DOI: https://dx.doi.org/10.4314/jasem.v23i4.31}

Copyright: Copyright $(0) 2019$ Onyeoru. This is an open access article distributed under the Creative Commons Attribution License (CCL), which permits unrestricted use, distribution, and reproduction in any medium, provided the original work is properly cited.

Dates: Received: 19 October 2018; Revised: 22 March 2019; Accepted 13 April 2019

Keyword: Power Utility Companies (PUC), Consumers, Suppliers, Electricity, Bills, Energy Consumption.

The high charges of bills by suppliers of electricity in Nigeria have in no small measures further aggravated the suffering of the consumers of electricity who are made to pay for high charges of power not supplied and consumed at all. A situation where consumers are left at the mercies of the supplier of power in Nigeria has called for a great concern to individuals and the general public. Many cases are in law courts contesting the rationale behind the illegalities of the present methods of bill assessment by suppliers of electricity in Nigeria to their numerous customers. Some of the these cases are that, meters are not provided by suppliers of electricity to determine accurate consumption by users or that meters when provided and installed are not well read to determine the actual consumption of power supplied. Many a time, the power service providers uses what they called Estimated Billing System (EBS) to charge consumes of their consumptions. This process has encouraged lot of lapses in the power supply industries. It did not only incubate and hatched corruption in the highest ebb but also breeds laziness and lousiness among staff of the power companies. This single act has made electricity consumer who are at the receiving ends to take the responsibilities of the supplier of electricity in order to access power supply. This act of negligence and derection of duty on the part of the suppliers of power has also led to poor economic growth and development most especially in Nigeria. This paper therefore seeks ways to analyse and evaluate the present methods of electricity billing in Nigeria and possibly proffer solution of better ways to redress the pending issues thereof. Commercial electric power in Nigeria is produced as alternating current through a silent, superficially limitless energy source that can be generated at power stations. The utilization of electrical energy is a pivotal to the development of any nation and it is directly correlated with a healthy economic growth (Kesere and Hoskins, 2012), Nigeria is a highly populated western African country. On rough evaluation, only about $40 \%$ of Nigerians are connected to the national energy grid. This percentage of Nigerian who actually have electric power supplied to them still suffer electric power problem around $60 \%$ of the time. (Aliyu and Saleh 2013). Nigeria, through one of the largest primary energy produces in the world still struggle to generate adequate electricity to support its economy and giant population. Regular and reliable electricity supply is therefore significant for industrialization and economic development. (Oluwasegun, 2015). The world today has become deeply dependent upon the continuous availability of electrical power. In Nigeria, commercial power is made available with the aid of a nation wide grid, interconnecting numerous generating stations to the loads. This grid must supply basic national needs of residential, lighting, heating, refrigeration, air conditioning and transportation as well as critical supply to governmental, industrial, financial, commercial, medical and other communities. 
Therefore, available evidence have shown that consumers of electricity have not had it any better inspite of the enormous public investment in the power sector. Industry players have attributed the dismal performance of the sector to bundling of the sector and have attributed it to the enjoyment of state monopoly and have accordingly called for privatization. In response to the clarion calls the government not only unbundled but also privatized. There is therefore the need to identify the customers and final consumers their experiences with service satisfactory evaluate the problems and use the result of the evaluation to assess the performance of service providers (Abdullateef, 2004). As the World economy becomes increasingly dependent on Technology that requires highly reliable electric power, reliable and qualitative electricity has been observed as a sine qua non element for modern living (Ali et al., 2004).On a global scale, reliable electric power availability has been observed as effective and indispensable machinery for industrial and economic growth of any nation (Megbowon and Onyebisi 2005)Therefore by its importance in the society and it's necessity for national economic growth, Electrical Energy Supply is expected to be available 24 a day (Jide et al., 2011).Based on this importance, it is expected that electric power utilities through out the World must ensure they meet customer demands at a resonable level of service reliability (Jide et al., 2011). From the above therefore, it can be infered that charges as bills sent to consumers of Electricity by public power suppliers is on the high side and does not comesurate the amount of electricity supplied.This abysmal charges has called for great concern both from government and individual consumers of public electricity in Nigeria . The power utility companies have failed in the discharge of their duties and violated the extent laws establishing them to provide adequate electricity power to meet the yearning demand of the people. Instead of providing a level field playing ground to enable the consumers of electricity to pay as they consumed, they rather resort to illegal methods of extorting and exploiting the poor masses by estimating the bills of the consumers. In some cases, even when meters are available, the meters are not read at all or are read and wrongly interpreted intentionally. This scenario has left so many consumers most especially the rural dwellers in delima as they rather choose to abandon the use of public power supply for individual means of power supply. This on other hand has made them to suffer huge economic losses to fossil fuel and other alternative means of power Supply.

The objective of this paper is to measure and evaluate electricity bills sent by Power Utility Companies to Consumers in Nigeria.

\section{MATERIALS AND METHODS}

Data obtained for this investigation was derived from sampling of bills per month sent by PUC to consumers of Electricity in some selected Urban, Rural and SemiUrban areas in Delta State. Bills sent by PUC was obtained from consumers of electricity in area under investigation and examined.Actual Meter Readings in those areas was also obtained,and was used to calculate for the actual bills of consumption of consumers. The operational tarrif regime used by PUC in the area investigated is $\$ 24$ per $\mathrm{kw} / \mathrm{h}$. In Nigeria, billing structure (Nwaoko, 2006) is given by

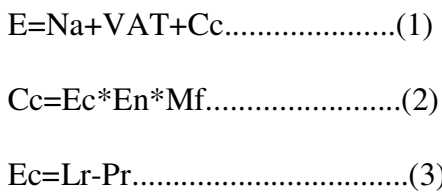

$\mathrm{Ec}=\mathrm{Lr}-\mathrm{Pr}$

Where $\mathrm{Na}=\mathrm{Net}$ arrears, VAT $=$ Value Added Tax, $\mathrm{Cc}=$ Current Charge, Ec=Energy Consumed, Lr=Last Meter Reading, Pr=Present Meter Reading, $\mathrm{En}=$ Energy Charge per $\mathrm{kw} / \mathrm{h}$, and $\mathrm{Mf}=$ Multiplying factor

\section{RESULT AND DISCUSSION}

Results obtained from the finding are presented and analyzed in this section. See tables 1 to 4 . In this study, existing methods of electricity measurement and Billing by to Power Utility Company (PUC) such as estimated billing system, wrong meter reading by PUC staff etc were closely examined. Similarly, measurement, evaluation, and calculation of actual electricity consumed in some selected houses in both Urban, Semi-Urban and Rural Communities were carried out. The values obtained from the investigation were as shown in tables 1 to 4 and average values plotted as shown in figure land the results were compared and analyzed. First and foremost, the values obtained from the present energy billing system sent by PUC to consumers in all the areas investigated were generally higher than the actual calculated values of this research study. This shows that PUC present method of billing is inaccurate. A closer look at the Tables 1-4 and figure 1 shows that the variations of the contemporary method of energy billing plotted against energy consumed in $(\mathrm{Kw} / \mathrm{h})$ is solemn exponential as a higher rise and fall are noticed along the length of the curve in all cases. This is not the same in the case of the results obtained from this research study. The rise and fall along the curve is proportional to the energy consumed because billing was purely based on real energy consumption. 
Table 1: Result obtained from urban consumers

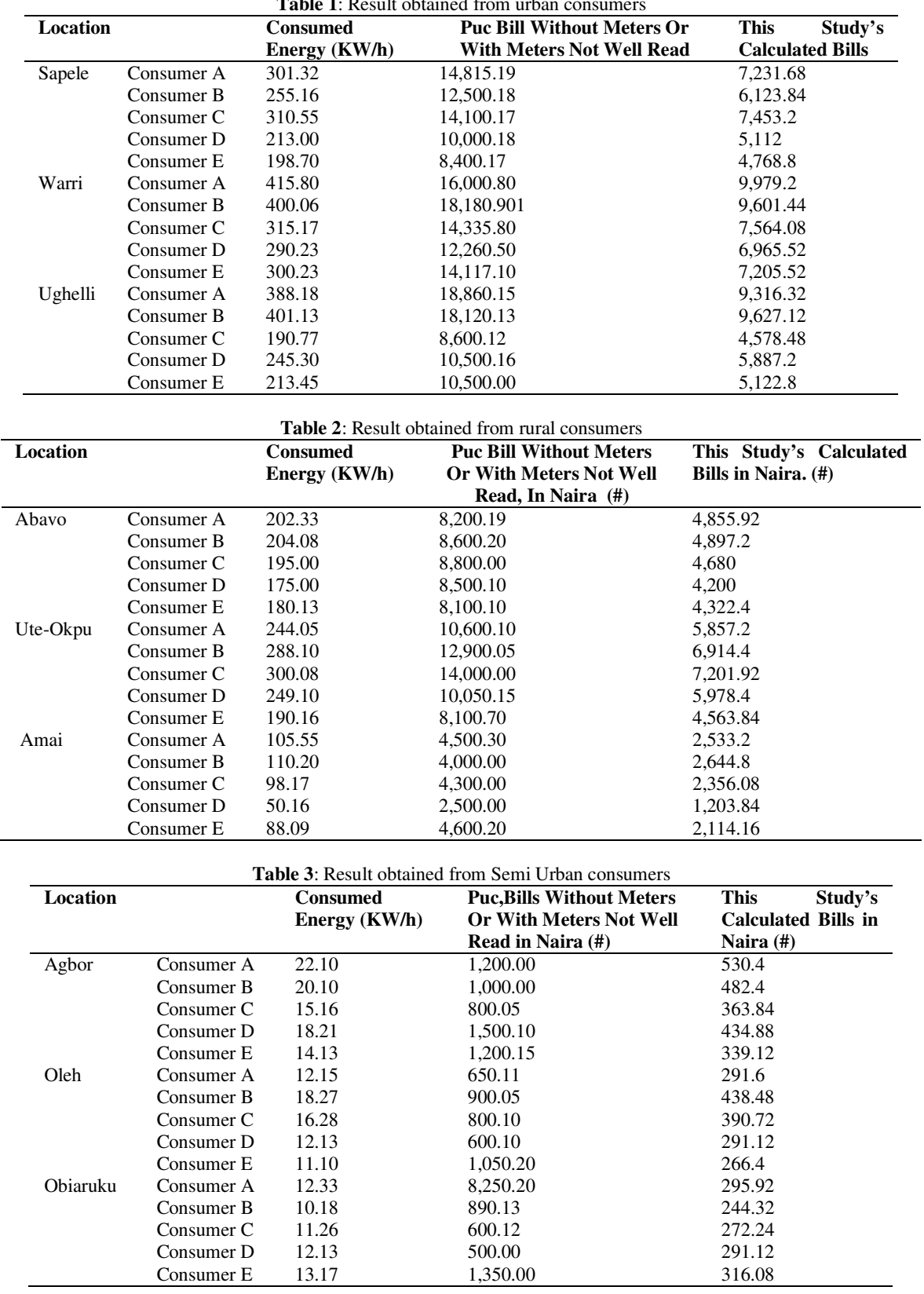

Significance of Result and Applications: The results obtained in this research are significant because it has revealed the concept of sending bills to consumers of electricity by PUC without adequate metering. It has also provided an accurate method of electricity billing that could engender level playing field for both suppliers and consumer of electricity nationwide. The present methods of electricity billing in Nigeria have negative effects on the customers as well as on the staff of any supply authority. On the consumers, the tendency not to pay the bill is there especially when the supply is irregular and the bill sent is high. How can a consumer pay a bill that is almost five times the bill he would pay if the supply is regular and meter accurately read? This has led to accumulated bills that are unpaid by the consumers and this practice is causing the heavy unpaid bill accrued to PUC. 
Table 4: Comparison of the Average Results Obtained from the Areas Under Investigation.

\begin{tabular}{|c|c|c|c|}
\hline Location & $\begin{array}{l}\text { Average } \quad \text { Energy } \\
\text { Consumed }(\mathrm{kw} / \mathrm{h})\end{array}$ & $\begin{array}{l}\text { Average Puc Bills Without } \\
\text { Meters Or With Meters Not } \\
\text { Well Read In Naira (\#) }\end{array}$ & $\begin{array}{l}\text { Average This } \\
\text { Study's Calculated } \\
\text { Bills In Naira (\#) }\end{array}$ \\
\hline Sapele & 255.75 & $9,143.14$ & 6,138 \\
\hline Warri & 344.37 & $14,979.02$ & $8,264.88$ \\
\hline Ughelli & 57.55 & $13,316.11$ & $5,043.12$ \\
\hline Agbor & 191.31 & $3,300.06$ & 4,596 \\
\hline Oleh & 254.30 & 800.11 & $6,103.2$ \\
\hline Obiaruku & 90.43 & $2,318.09$ & $2,170.32$ \\
\hline Abavo & 13.50 & 844.12 & 324 \\
\hline Ute-okpu & 11.56 & $11,144.06$ & 277.44 \\
\hline Amai & 11.81 & $3,908.1$ & 283.44 \\
\hline
\end{tabular}

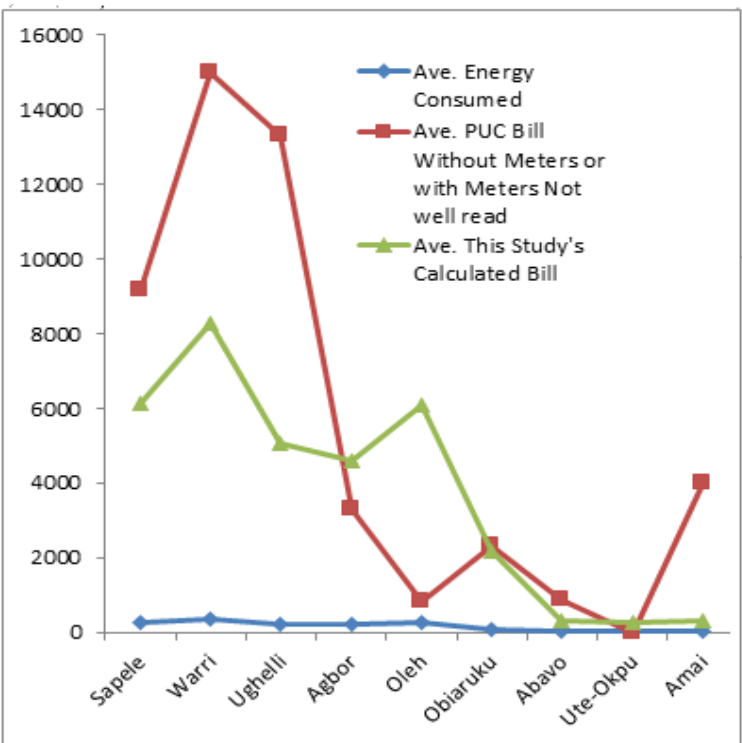

Fig1: Energy Consumed, PUC Bill and This Study Calculated Bills

The staff on the other hand is also affected. The rate at which they respond to customer complaint is reduced. It takes days if not weeks to clear a simple fault that ordinary would have taken some few hours. The reason is that whether there is supply or not at the end of the month, customers will receive bill. This then breads laziness on the part of staff concerned. This present method of billing has also increased the corruption level of staff. Insincere consumers would want to pay his/her bills which are quite high with the tendency to bribe the marketer with a token so that the lot of the bill can be "wipe off'. This corrupt archive has become a constant feature in the life of some marketers of electricity most especially at the Power Distribution Companies in Nigeria.

Conclusion: Many electric energy consumers' premises are not metered, accordingly, bills are sent to them. In some cases, meters are not read, but bills by PUC sent to consumers, without meters are on the high side. It is very necessary for consumer to be billed for the actual energy consumed. That PUC should ensure that all's premises are metered and accordingly accurate bill be sent to them by employing the use of the Smart device for energy meter (SD) for metering, monitory and control of its supplies, because the results obtained from this research findings show that the present methods of bill assement by Public Utility Companies are grossly inadequate, inefficient, and ineffective as they do not reflect the actual consumptions by Consumers.

\section{REFRENCES}

Abdulateef, U (2004). Determinant of Electricity Consumer Satisfaction in selected Electricity Distribution in Nigeria. Implication for Regulatory http//acessweb.com/journal-

Aliyu, R; Saleh, H (2013). Nigerian Electricity Crisis: power generation capacity expansion and environmental ramifications energy. 61C81, pp. 354-367

Popoola, JJ; Ponnle, AA; Ale, TO (2011). Reliability worth Assessment of Electric Power Utility in 
Nigeria: Residential Customer Survey Results. AU J.T. 14(3): 217-224.

Kaseke, N; Hosking, S. (2013). Sub-Saharan African Electricity Supply Inadequacy: Implications S.L. Organization for Social Science Research in Eastern and Southern African, pp. 113-132
Megbowon, IO; Onyebisi, TO (2005). A Reliability Assessment of South Western Transmission Lines of the Nigerian National Grid.

Oluwasegun, AS (2015). The Baratric Electric Power Supply in Nigeria: Causes and Remedy, 27 May, 2016. Pp.5.

Kuale, PA; Otuagoma, SO (2012). Electric Bill Payments by Unmetered Consumers. J. Engineer. Res. Appl. Sci. 4. 22-27 